\title{
Personality Similarity in Twins Reared Apart and Together
}

\author{
Auke Tellegen \\ University of Minnesota
}

Thomas J. Bouchard, Jr., Kimerly J. Wilcox, and
Nancy L. Segal
University of Minnesota

\author{
David T. Lykken \\ Departments of Psychology and Psychiatry \\ University of Minnesota \\ Stephen Rich \\ Department of Pathology and Laboratory Medicine and \\ Institute of Human Genetics \\ University of Minnesota
}

\begin{abstract}
We administered the Multidimensional Personality Questionnaire (MPQ) to 217 monozygotic and 114 dizygotic reared-together adult twin pairs and 44 monozygotic and 27 dizygotic reared-apart adult twin pairs. A four-parameter biometric model (incorporating genetic, additive versus nonadditive, shared family-environment, and unshared environment components) and five reduced models were fitted through maximum-likelihood techniques to data obtained with the 11 primary MPQ scales and its 3 higher order scales. Solely environmental models did not fit any of the scales. Although the other reduced models, including the simple additive model, did fit many of the scales, only the full model provided a satisfactory fit for all scales. Heritabilities estimated by the full model ranged from .39 to .58 . Consistent with previous reports, but contrary to widely held beliefs, the overall contribution of a common family-environment component was small and negligible for all but 2 of the 14 personality measures. Evidence of significant nonadditive genetic effects, possibly emergenic (epistatic) in nature, was obtained for 3 of the measures.
\end{abstract}

Until recently, almost all knowledge regarding environmental and genetic causal influences on stable personality traits has come from studies of twins reared together. The findings have been both remarkable and puzzling. On the genetic side, regardless of the trait studied, the intraclass correlation for fraternal, or dizygotic $(\mathrm{DZ})$, twins has approached .25 ; that for identical, or monozygotic (MZ), twins has approached .50 (Goldsmith, 1983; Nichols, 1978). Application of the simplest genetic model, the Falconer (1960) formula for heritability, $\left[h^{2}=\right.$ $\left.2\left(R_{M Z}-R_{D Z}\right)\right]$, to those results yields a heritability of about .50 . This leaves $50 \%$ of the variance to systematic environmental influences, measurement error, and temporal instability.

Particularly puzzling, and contrary to what many psychologists would predict, is the finding that almost none of the envi-

This research has been supported by grants from the University of Minnesota Graduate School, the Koch Charitable Foundation, the Spencer Foundation, the National Science Foundation (BNS-7926654), the Pioneer Fund, and the Harcourt Brace Jovanovich Publishing Company.

We thank the following people for the time and effort they have given to testing the twins: Margaret Keyes, Jeff McHenry, Elizabeth Rengel, Susan Resnick, Joy Fisher, Jan Englander, and Ann Riggs. We are indebted to our colleagues and collaborators on the Minnesota Study of Twins Reared Apart project, Elke Eckert and Leonard Heston for their help and advice. We owe special thanks to our colleagues, Greg Carey and Matt McGue, for their valuable biometric advice and assistance. We also thank Jack Darley for his resolute and dedicated support and the Minneapolis War Memorial Blood Bank, Herbert Polesky, Director, for the blood testing.

Correspondence concerning this article should be addressed to Auke Tellegen, Department of Psychology, Elliott Hall, University of Minnesota, 75 East River Road, Minneapolis, Minnesota 55455. ronmental variance is due to sharing a common family environment. Loehlin and Nichols (1976) reached this conclusion on the basis of personality data collected on a large National Merit Scholarship twin sample. Eaves and Young (1981) carried out an informative additional analysis of Extraversion-Introversion and Neuroticism scores from the same twin sample, using a biometric model similar to the one to be reported in this article. They fitted three models to the data. The first model allowed for unshared environment effects and additive gene effects. The second allowed for two environmental effects: shared familyenvironment effects and unshared environment effects, but no genetic effects. The third specified the joint effect of all three. The results were straightforward: The second model, which only specified environmental parameters, did not fit the data for either sex or for the two sexes considered jointly. The first model, which assumes no common family-environment effect, fit all three cases and was as capable of fitting both sexes simultaneously (with identical parameter estimates) as it was of fitting the results of each sex separately. Adding the common familyenvironment effect did not improve the fit of the third model over the first. These results essentially confirmed Loehlin and Nichols's (1976) earlier analysis.

Loehlin and Nichols (1976) carried out many additional analyses of their data. In particular, they attempted to identify the effects of systematic within-family variations. Because identical twins share all of their genes, any differences between them must be environmental in origin. By relating within-pair zygosity-group differences in experiences to personality differences, they could answer questions such as, "Do identical twins who were dressed alike turn out to be more similar in personality than identical twins who were not?" The results were essentially negative. Greater similarity in the twins' experiences could ac- 
count for only a small fraction of the MZ twins' similarity in personality. Loehlin and Nichols (1976) concluded the following:

Thus, a consistent - though perplexing-pattern is emerging from the data (and it is not purely idiosyncratic to our study). Environment carries substantial weight in the determination of personality - it appears to account for at least half the variance - but that environment is one for which twin pairs are correlated close to zero. Attempts to treat twins alike do not lead to greater similarity between them. In short, in the personality domain we seem to see environmental effects that operate almost randomly with respect to the sorts of variables that psychologists (and other people) have traditionally deemed important in personality development. (p. 92)

However, adoption data (Scarr, Weber, Weinberg, \& Witting, 1981a; 1981b) and nontwin family data (Ahern, Johnson, Wilson, McClearn, \& Vandenberg, 1982; Loehlin, Horn, \& Willerman, 1981) complicate the picture. Scarr et al. (1981a) found not only modest correlations between nonbiological relatives (.04 between adoptive parent and child and .07 between adoptive siblings), confirming the slight influence of a common family environment on personality, but also low correlations for first-degree biological relatives (.15 between parent and child and .20 between siblings). These latter figures are not unlike those compiled by Loehlin et al. (1981) for first-degree relatives. In addition, Ahern et al. (1982) reported a parent-offspring correlation of about .12 and a sibling correlation of about .10, on the basis of 54 scales. Ahern et al. suggested that the heritability of personality estimated from nontwin family data approaches .20. Scarr et al. (1981a) suggested a figure between .14 and .22 .

Price, Vandenberg, lyer, and Williams (1982) fitted a random effects linear model to six personality measures obtained from the extended families of $\mathrm{MZ}$ and $\mathrm{DZ}$ twins in the Swedish twin registry. Their analysis incorporated 13 consanguineous relationships (e.g., $\mathrm{MZ}$ twin pairs, DZ twin pairs, siblings, and mother-child pairs) and 9 nonconsanguineous relationships (e.g., spouses, siblings-in-law through MZ twins). The analysis yielded estimates of additive variance of nearly zero for four traits and very modest estimates for the remaining two traits (.04 and .07 , respectively). Hewitt (1984) has argued, however, that the Price et al. (1982) analysis does not adequately support their conclusions because the data also fit a simple additive model that yields heritability estimates of about .50 (cf. also Heath, Martin, \& Eaves, 1984). With the exception of Hewitt's reanalysis, conclusions based on twin data and nontwin family data appear to be at odds. Even Hewitt's critique is not so much a refutation of the Price et al. conclusions as a demonstration that their data fit contrasting models and are not decisive. How are we to proceed given these seeming discrepancies?

First, parent-offspring data have the disadvantage of being collected when subjects are at different ages. If personality traits are expressed differently at different ages (i.e., some personality traits may be age dependent for genetic or environmental reasons), then the parent-offspring data simply do not reflect the same phenomena as the twin data. The sibling data are not subject to this problem to the same degree, and they do show a slightly higher correlation in some studies. Only twin data have the obvious advantage of involving pairs of individuals of identical age, but the twin design has its own problems. Twin methodology depends on the assumption of equal environmental in- fluences on both $M Z$ and $D Z$ twins and unbiased sampling of $\mathrm{MZ}$ and $\mathrm{DZ}$ twins from the twin population. Although there is considerable evidence to support the assumption of equal traitrelevant environments (Bouchard, 1984), many investigators still find it unpalatable. This is one instance in which the study of twins reared apart can contribute critical new information, a point to which we return shortly.

Second, most previous analyses of personality data have suggested that a simple additive model, reflecting the contribution of an unspecified number of independently segregating genetic factors, explains the data adequately. If genetic effects are entirely additive and there are no shared family-environment effects, then the $\mathrm{DZ}$ correlations should be about half the size of the MZ correlations. It has been observed, however, that for some traits the $\mathrm{DZ}$ correlations, like nontwin familial correlations, are clearly less than one half the size of MZ correlations (e.g., Lykken, 1982). This suggests nonadditive genetic effects, particularly dominance, or if $\mathrm{DZ}$ correlations are very low, epistasis (i.e., interaction between nonallelic genes).

Lykken and his colleagues (Lykken, 1982; Lykken \& Bouchard, 1983/84; Lykken, Tellegen, \& lacono, 1982) have suggested that a complex form of epistasis, called emergenesis, may account for a significant portion of the discrepancy between twin data and Parent $\times$ Offspring and sibling data. Particularly in the case of epistasis, genetic effects could be both substantial and nonfamilial. In those instances, rather than exaggerating "the degree to which personality differences are explained by genetic differences" (Scarr et al., 1981a, pp. 896-897), twin data may tell a truer story, and the data based on nontwins may underestimate the actual impact of genetic factors.

Another striking phenomenon in the personality domain is the apparent lack of differences in heritability among personality variables. Loehlin and Nichols's (1976) findings are a case in point. Their twin personality data involved a well-known instrument, the California Psychological Inventory (CPI; Megargee, 1972), and revealed that the scales of this multimeasure instrument have highly similar heritabilities. The differential heritability of personality variables (or the lack thereof) has subsequently become a subject of some controversy (Carey, Goldsmith, Tellegen, \& Gottesman, 1978; Carey \& Rice, 1983; Loehlin, 1982; Zonderman, 1982). What on the surface may appear to be lack of differential heritability among psychologically diverse scales may in reality reflect substantial content (and item) overlap and high correlations among scales in inventories such as the CPI (Carey et al., 1978).

Even factor analytically constructed multiscale inventories usually reflect substantial saturation with only a small number of higher order superfactors, particularly Positive Emotionality (extraversion) and Negative Emotionality (neuroticism). Watson and Clark (1984) have discussed the diverse names given to what are essentially Negative Emotionality measures, reflecting the wide scope of that dimension. If, in addition, the superfactors themselves do not differ much in heritability, then only the addition of scales that are not excessively superfactor saturated could lead to evidence of differential heritability. Loehlin

\footnotetext{
${ }^{1}$ Environment, as defined by these authors, presumably also includes measurement error and nonsystematic changes over time.
} 
(1982) has adduced evidence that this is in fact the case. Given all of the problems involving subject samples and choice of measures, it is desirable to cross-check the various findings discussed earlier using a design and instruments that avoid these difficulties.

Our study makes use of a design that has never, to our knowledge, been implemented: the simultaneous use of $M Z$ and $D Z$ twins reared together (MZTs and DZTs, respectively) and reared apart (MZAs and DZAs, respectively). Although several personality findings have been reported on MZAs (cf. Bouchard, 1984, Table 10), we know of no one who has ever reported personality data gathered on all four groups using the same personality inventory. This design circumvents many of the problems discussed earlier. First, the use of twins avoids the problem of testing at different ages. Second, the use of twins reared apart, although possibly subject to other flaws (Bouchard, 1984), relieves us of the assumption of equal environmental similarity for $\mathrm{MZ}$ and $\mathrm{DZ}$ twins. Because they were placed for adoption at such a young age, placement practices are unlikely to have been different for MZAs and DZAs (cf. Bouchard, 1984). Finally, with respect to the role of a common environment, it is difficult to believe that twins reared apart (even if placed in somewhat similar homes) would have the similarity in trait-relevant environments that are experienced by twins reared together. Under a purely common-environment hypothesis, $\mathrm{MZ}$ twins and DZ twins would be expected to show the same degree of within-twin similarity, but twins reared together should exhibit greater similarity than twins reared apart. The biometric model allowed us to test specific hypotheses of this type.

To test the hypothesis of differential heritability of personality variables, we found it necessary to use an instrument composed of relatively independent scales. We used the Multidimensional Personality Questionnaire (MPQ), formerly called the Differential Personality Questionnaire (DPQ), in this study. The MPQ (discussed in more detail in the Method section) was developed using a factor analytic strategy (Tellegen, 1982). Its scales, compared with those in other multiscale inventories, are relatively independent but can still be meaningfully integrated into higher order factor measures. The latter correspond closely to the superfactor scales that were developed by Eysenck and Eysenck (1975) and analyzed by Eaves and Young (1981) and many others. The MPQ thus permitted us to assess differential heritability on lower as well as higher order factor levels.

\section{Method}

\section{Samples}

The $\mathrm{MZ}$ and $\mathrm{DZ}$ twins reared together participated in the Minnesota Twin Study between 1970 and 1984. Details of their recruitment are reported in Lykken (1982) and Lykken et al. (1982). The zygosity diagnosis of all twins included in this study was based on analyses of eight blood group systems, four serum proteins, six red blood cell enzymes, fingerprint ridgecount, ponderal index, and cephalic index. Probability of misdiagnosis is less than .001 (Lykken, 1978).

The MZA and DZA twins participated in the Minnesota Study of Twins Reared Apart between 1979 and 1986. Details of their recruitment are reported in Bouchard (1984) and references cited therein. The twins' age at separation ranged from birth to 4.5 years, with a median of 0.2 years. Separation time (number of years from separation to first
Table 1

Sample Sizes, Percentage Females, and Means and Standard Deviations for Age for $M Z A, D Z A, M Z T$, and $D Z T$ Twins

\begin{tabular}{llllc}
\hline Descriptive statistics & MZA & DZA & MZT & DZT \\
\hline Total sample size (sets) & $44^{\mathrm{a}, \mathrm{b}}$ & $27^{\mathrm{b}}$ & 217 & 114 \\
Percentage females & 66.7 & 75.5 & 65.0 & 64.9 \\
Mean age (years) & 40.7 & 41.1 & 23.5 & 19.8 \\
SD of age & 12.0 & 11.3 & 11.1 & 4.3 \\
\hline
\end{tabular}

Note. $\mathrm{MZA}=$ Monozygotic twins reared apart, $\mathrm{DZA}=$ dizygotic twins reared apart, $\mathrm{MZT}=$ monozygotic twins reared together, and DZT = dizygotic twins reared together.

${ }^{a}$ Two MZA male triplet sets entered as 1 set each. ${ }^{\text {b }}$ One reared-apart triplet set (two MZA females and one male) entered as 1 MZA pair and 2 DZA pairs.

contact) ranged from 0 to 64 years, with a median of 33.8 years. ${ }^{2}$ Zygosity was determined for all reared-apart twins in the same way as for reared-together twins. All twin pairs used in this study were of the same sex, except for 4 opposite-sex DZA twin pairs. Descriptive statistics on the samples are presented in Table 1.

\section{Personality Inventory}

The MPQ is a factor analytically developed self-report instrument. Its scales represent 11 primary personality dimensions and 3 higher order traits; alpha coefficients range from .76 to .89 , with a median of $.85 ; 30$ day test-retest correlations range from .82 to .92 , with a median of .89 (Tellegen, 1982, 1985). Particular care was taken during the development of the MPQ to achieve relatively independent primary scales. Thus, unlike the CPI used in the Loehlin and Nichols (1976) study, we had a number of scales that are not primarily superfactor markers. We did, however, essentially tap these factors at the higher order level.

The higher order MPQ scales are interpreted as self-report dimensions describing basic parameters of emotional and behavioral regulation. Factor 1, Positive Emotionality, is primarily associated with the MPQ Well-Being, Social Potency, Achievement, and Social Closeness scales and has clear "extraverted" features. High scorers on these scales present themselves as being engaged in active, pleasurable, and efficacious transactions with their environment and as being ready to experience the positive emotions congruent with these involvements. Low scorers report few of these pleasurable transactions, a lower degree of self-efficacy, a higher threshold for experiencing positive affect, and a tendency toward depressive, nonpleasurable disengagement. Positive Emotionality is related to Eysenck's Extraversion (E; Eysenck \& Eysenck, 1975) and clearly resembles the Norman-Goldberg Surgency dimension (Goldberg, 1981).

Factor 2, Negative Emotionality, is primarily associated with the MPQ Stress-Reaction, Alienation, and Aggression scales. High scorers describe themselves as being unpleasurably engaged, stressed and harassed, and prone to experiencing strong negative emotions such as anxiety and anger. Low scorers convey a less "catastrophizing" picture, a higher threshold for negative affect, greater resiliency under stress (Block, 1964), and a tendency toward phlegmatic, non-unpleasurable disengagement. This dimension shares important features with Eysenck's Neuroticism (N) and Norman-Goldberg's (reversed) Agreeability and (reversed) Emotional Stability factors, particularly the latter.

\footnotetext{
${ }^{2}$ Separation time was arbitrarily set at zero for twin pairs who were reared in different homes but who had had periodic contact during childhood.
} 
The affective interpretation of higher order MPQ Trait Factors 1 and 2 is supported by their convergent-discriminant relations to the state dimensions of Positive and Negative Affect, respectively (Tellegen, 1982), which dominate measures of current mood (Watson \& Tellegen, 1985). The same pattern of relations to Positive and Negative Affect has been reported for Eysenck's Extraversion and Neuroticism scales, respectively (Costa \& McCrae, 1980; Warr, Barter, \& Brownbridge, 1983).

The third higher order MPQ dimension, Constraint, is most strongly associated with the MPQ Control, Harm Avoidance, and Traditionalism scales. High scorers on these scales describe themselves as being restrained, cautious, avoiding dangerous kinds of excitement and thrills, deferential, and conventional. Low scorers present a picture of impulsiveness, fearless sensation seeking, and rejection of conventional strictures on their behavior. Constraint is most clearly related to Eysenck's (reversed) Psychoticism (P) and the Norman-Goldberg Conscientiousness factor.

A more detailed exposition of this three-dimensional scheme and its conceptual relations, particularly to Eysenck and Eysenck's (1975), Gray's $(1973,1981)$, and psychodynamic views, has appeared elsewhere (Tellegen, 1985). Depue, Krauss, and Spoont (1987) have presented an entirely consonant interpretation of Positive Emotionality as a "behavioral engagement" dimension and have emphasized its particular relevance to euphoric and depressive diatheses. Watson and Clark (1984) have provided a comprehensive interpretive review of Negative Emotionality, documenting the breadth of its manifestations.

\section{Analytic Procedures}

Age- and sex-correction of personality scores. Raw scores on the MPQ were corrected for age, age ${ }^{2}$, and Age $\times$ Sex using the combined samples of MZT, DZT, MZA, and DZA twins. Scores were then standardized $(M=0, S D=1)$. The regression procedures are described in McGue and Bouchard (1984).

Biometric models. Although intraclass correlations are often informative and are presented here, for analytic purposes they can be misleading if $\mathrm{MZ}$ and $\mathrm{DZ}$ variances differ. Biometric geneticists, following Jinks and Fulker (1970), therefore, prefer analyzing variances over correlations. We also take this approach in this article. The expected values of the between (B) and within (W) mean squares of each twin group are expressed as appropriately weighted sums of the particular environmental and genetic variance components that are incorporated into one's chosen model. The weights (coefficients) are estimated from the observed mean squares. For presentations of biometric approaches, see Eaves (1978, 1982); Eaves, Last, Young, and Martin (1978); Jinks and Fulker (1970); Martin, Eaves, Kearsey, and Davies (1978); Nance and Corey (1976); and Rose et al. (1980).

Our full model decomposes the phenotypic variance of each trait into three main components: genetic, shared family environment, and unshared environment, each estimated as a parameter. The genetic component is further analyzed in terms of an additive subcomponent (reflecting the contribution of an unspecified number of independently segregating genetic factors) and a nonadditive component. Specifically, the model, as developed by G. Carey (personal communication, 1986), exploits the joint availability of twins reared together and apart to estimate an "additivity" parameter. This fourth parameter permits us in principle (albeit with low power, due to the small number of DZAs) to distinguish traits that are primarily additive from ones that are primarily nonadditive. Marked nonadditivity is attributable to epistasis, a genetic effect of particular interest to us, as explained earlier. As for environmental components, the shared family-environment component represents the contribution of those distinctive family characteristics (distinguishing families from one another) that influence individuals reared in the same family in the same way. The unshared environment
Table 2

Biometric Model Specifying Genetic and Environmental Components of Variance of Between (B) and Within (W) Mean Squares of Twins Reared Together and Apart

\begin{tabular}{lccc}
\hline & & \multicolumn{2}{c}{ Environmental } \\
\cline { 3 - 4 } Mean square & Genetic & Shared familial & Unshared \\
\hline B(MZT) & 2 & 2 & 1 \\
W(MZT) & 0 & 0 & 1 \\
B(MZA) & 2 & 1 & 1 \\
W(MZA) & 0 & 1 & 1 \\
B(DZT) & $1+C$ & 2 & 1 \\
W(DZT) & $1-C$ & 0 & 1 \\
B(DZA) & $1+C$ & 1 & 1 \\
W(DZA) & $1-C$ & 1 & 1 \\
\hline
\end{tabular}

Note. MZT = Monozygotic twins reared together, $\mathrm{MZA}=$ monozygotic twins reared apart, DZT = dizygotic twins reared together, and $\mathrm{DZA}=$ dizygotic twins reared apart. $\mathrm{C}$ is a parameter ranging between 0 and .5 , reflecting degree of additive versus nonadditive genetic control. If $C$ equals .5 , the genetic effects are entirely additive; if $C$ approaches 0 , the genetic effects are increasingly nonadditive, reflecting an unknown mixture of additive, dominant, and epistatic effects; and if $C$ equals 0 , the genetic effects are entirely epistatic.

component reflects, among other things, measurement error and state fluctuations.

The full model is displayed in Table 2. The table shows how the B and $W$ mean squares can be expressed in terms of the four parameters mentioned earlier: genetic, additive, shared family environment, and unshared environment. The model can be examined by determining how it specifies expected genetic and environmental twin correlations, as follows.

Using the formula for the intraclass correlation, $\mathrm{R}=(\mathrm{B}-\mathrm{W}) /(\mathrm{B}+$ W), we learn from Table 2 that the genetic correlation for $M Z$ twins equals $(2-0) /(2+0)=1$, as required (see the Genetic column, rows 1 and 2 or 3 and 4). For DZ twins, if the additivity parameter $C$ is set at its maximum value of 5 , the genetic correlation equals $[(1+.5)-(1-$ $.5)] /[(1+.5)+(1-.5)]=.5$ (see Genetic column, rows 5 and 6 or 7 and 8 ), in accordance with the theoretical expectation that the additive genetic correlation between $\mathrm{DZ}$ cotwins is half that of $\mathrm{MZ}$ cotwins. If $\mathrm{C}$ is set at its minimum value of 0 , then the genetic $\mathrm{DZ}$ correlation, computed in the same way, equals $(1-1) /(1+1)=0$, showing that complete epistasis eliminates any genetic correlation between $\mathrm{DZ}$ cotwins. Turning to environmental correlations, we can see from the appropriate rows in the Shared Familial-Environmental column of Table 2 that for twins reared together and apart, the shared family-environment correlation equals 1 and 0 , respectively. The unshared environment correlation equals 0 by definition, which is the value entailed by the entries in the last column of the table.

The four parameters are estimated and statistically evaluated with the maximum likelihood method described by Martin et al. (1978). Expressed as proportions of the total variance, these estimates are the heritability (in the broad sense, incorporating both the additive and nonadditive components), additivity versus nonadditivity, shared family-"environmentality," and unshared "environmentality" values that, given the model, best fit the data for a given scale.

In addition to the full model shown in Table 2, one can also evaluate simpler (reduced) versions. This is done by assigning a priori values to one or more of the parameters while fitting the remaining ones to the data. In this analysis, six models were investigated: (1) unshared environment effects; (2) shared family-environment and unshared environment effects; (3) additive genetic and unshared environment effects; (4) 
Table 3

Intraclass Correlations for 11 Primary Scales and 3 Higher Order Scales for the Multidimensional Personality Questionnaire for Four Kinship Groups

\begin{tabular}{lcccc}
\hline \multicolumn{1}{c}{ Scale } & MZA & DZA & MZT & DZT \\
\hline Primary & & & & \\
Well-Being & .48 & .18 & .58 & .23 \\
Social Potency & .56 & .27 & .65 & .08 \\
Achievement & .36 & .07 & .51 & .13 \\
Social Closeness & .29 & .30 & .57 & .24 \\
Stress Reaction & .61 & .27 & .52 & .24 \\
Alienation & .48 & .18 & .55 & .38 \\
Aggression & .46 & .06 & .43 & .14 \\
Control & .50 & .03 & .41 & -.06 \\
Harm Avoidance & .49 & .24 & .55 & .17 \\
Traditionalism & .53 & .39 & .50 & .47 \\
Absorption & .61 & .21 & .49 & .41 \\
Higher order & & & & \\
$\quad$ Positive Emotionality & .34 & -.07 & .63 & .18 \\
Negative Emotionality & .61 & .29 & .54 & .41 \\
Constraint & .57 & .04 & .58 & .25 \\
\hline
\end{tabular}

Note. $\mathrm{MZA}=$ Monozygotic twin pairs reared apart $(n=44), \mathrm{DZA}=$ dizygotic twin pairs reared apart $(n=27), \mathrm{MZT}=$ monozygotic twin pairs reared together $(n=217)$, and $\mathrm{DZT}=$ dizygotic twin pairs reared together $(n=114)$.

additive genetic, shared family-environment, and unshared environment effects; (5) additive and nonadditive genetic effects, and unshared environment effects; and (6) the complete four-parameter model (additive and nonadditive genetic effects, as well as shared family- and unshared environment effects). For each of the six models, the estimates were made through maximum likelihood techniques and were evaluated by means of appropriate residual chi-square computations. Acceptance of a model required a nonsignificant chi-square. ${ }^{3}$

\section{Results}

\section{Descriptive Statistics}

We inspected the means and standard deviations of the MPQ raw scores of the four twin groups and found them to be comparable to those of other samples. The scale intercorrelations, computed separately for women and men, were likewise similar to those found in other samples. The results confirm the relative independence of the primary scales and justify our choice of this instrument to evaluate differential heritability of personality variables. Table 3 shows intraclass correlations for the four twin groups. The modest size of the DZA sample is reason for caution in comparing results for this group with the other twin samples. The DZA twins are, however, clearly much less similar than the MZA twins. Additionally, the correlations for the MZA and MZT samples are overall highly similar: The median correlations for the 11 primary MPQ scales are .49 and .52 , respectively. This pattern suggests that a purely environmental model will not provide an adequate explanation. The $B$ and $W$ mean squares on which our analyses are based are shown in Table 4.

\section{Biometric Analysis}

Of the reduced models, neither Model 1 nor Model 2, the two purely environmental models, came close to fitting the data for any of the 14 scales: The relevant chi-squares were all highly significant and large. The other four models fared substantially better. Model 3, the simple additive model, yielded an adequate fit for 11 of 14 scales, with the exception of the Well-Being, Control, and Positive Emotionality scales. Model 4, which adds the shared family-environment component as a parameter to Model 3, fit all scales except Well-Being and Control. Model 5 adds the nonadditive parameter to Model 3 and fit all scales except Well-Being. Finally, Model 6, the complete four-parameter model, provided a good fit for all 14 scales. The complete set of parameter estimates of Model 6 is presented in Table 5.

As Table 5 shows, the genetic parameter estimates (i.e., the heritabilities) range from .39 to .58 , with an average of .48 . Given the good fit of the simple additive genetic model (Model 3 ), it is not surprising that Table 5 does not show many instances of appreciable nonadditivity or shared family environmentality. Nevertheless, for three scales-Social Potency, Control, and Positive Emotionality-the estimates of the C parameter indicate statistically significant nonadditivity and are low enough to be consistent with an emergenic (epistatic) interpretation. We saw already that of these three scales, Control and Positive Emotionality did not fit the simple additive genetic Model 3. The third scale, Social Potency, although accommodated by all four genetic models, fit Models 5 and 6 (which contain the [non]additivity parameter) better than Models 3 and 4. With increased power that can, for example, be attained by increasing the size of the DZA sample, additional evidence of nonadditivity may be forthcoming. Table 5 shows significant familial effects for just two scales, Social Closeness and Positive Emotionality.

\section{Discussion}

These results confirm and extend earlier findings and have several implications for current thinking and future research concerning determinants of variation in personality. First, our analyses indicate that, on average, about $50 \%$ of measured personality diversity can be attributed to genetic diversity. This re-

\footnotetext{
${ }^{3}$ It is still customary practice to arrive at conclusions about data by accepting or rejecting null hypotheses on the basis of statistical significance tests. We have also followed this approach. One reason is that null hypothesis testing, given our sample sizes and the power of the analyses, appears to lead to reasonable comparisons of the extent to which the several models adequately represent major features of the data. In addition, we did not wish to deflect attention from our present topic, which is substantive and not methodological. Anticipating future discussions, however, we wish to be on record as viewing null hypothesis testing as inherently flawed. Given large enough samples, one can be sure that even our full model will "significantly" fail to fit the data. All models are simplications and their falsehood can be assumed without conducting significance tests. Psychologists need not spend time deciding the truth or falsehood of their strictly false models. We can do better by attempting to assess the degree to which alternative models of high content fit the data and to evaluate which model or models fit the data best. Although these issues have been widely discussed by structural-modeling specialists (e.g., Bentler \& Bonett, 1980; Cudeck \& Browne, 1983), they appear not to have been considered in applications of biometric genetic models to psychological data. For critical discussions of significance testing, see also Lykken (1968) and Meehl (1978).
} 
Table 4

Between $(B)$ and Within $(W)$ Mean Squares of Twins Reared Apart and Together for Multidimensional Personality Questionnaire Data

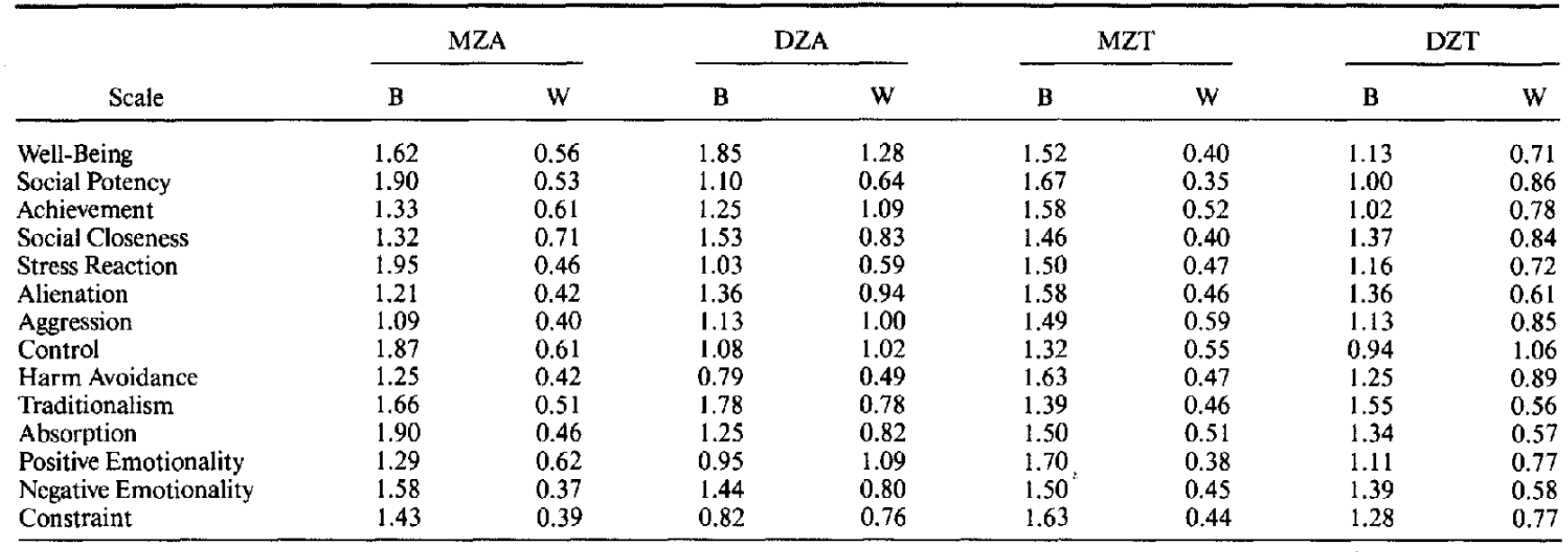

Note. $\mathrm{MZA}=$ Monozygotic twins reared apart, $\mathrm{DZA}=$ dizygotic twins reared apart, $\mathrm{MZT}=$ monozygotic twins reared together, and $\mathrm{DZT}=$ dizygotic twins reared together.

sult confirms previous findings and represents an extension to a wide range of distinctive personality characteristics. The remaining 50\% is technically classified as all environmental and includes the unshared environment effect that, in turn, includes measurement error and nontrait score fluctuations that reflect the influence of transient states on self-report trait measures. If one considers both the internal consistency and stability of personality scales (cf. Conley, 1984), it is not unreasonable to guess that not more than about 70 to $85 \%$ of the observed variance represents trait variance. Because the 15 to $30 \%$ nontrait variance is presumably confined to the environmental $50 \%$ of the observed variance, the environmentally based trait variance may not amount to more than 20 to $35 \%$, compared with the roughly $50 \%$ that is genetic in origin. Improving the consistency and stability of a trait scale should increase its measured genetic and trait-relevant environmental components, but not their relative magnitude. It seems reasonable, therefore, to conclude that personality differences are more influenced by genetic diversity than they are by environmental diversity.

Consistent with these observations is the absence of substantial shared family-environment effects in our data. Positive Emotionality and Social Closeness, however, yielded significant estimates of .22 and .19 , respectively. These results warrant some partially speculative comment.

Table 5

Estimates of Genetic and Environmental Variance Components From a Biometric Model Applied to Multidimensional Personality Questionnaire Data of Twins Reared Apart and Together

\begin{tabular}{|c|c|c|c|c|}
\hline \multirow[b]{2}{*}{ Scale } & \multicolumn{4}{|c|}{ Variance component } \\
\hline & Genetic & C parameter & Shared familial & Unshared \\
\hline Well-Being & $.48^{\mathrm{a}}(.08)$ & $.29(.16)$ & $.13(.09)$ & $.40^{\mathrm{a}}(.04)$ \\
\hline Social Potency & $.54^{\mathrm{a}}(.07)$ & $.05^{\mathrm{a}}(.21)$ & $.10(.08)$ & $.36^{\mathrm{a}}(.04)$ \\
\hline Achievement & $.39^{\mathrm{a}}(.10)$ & $.13 \quad(.27)$ & $.11(.11)$ & $.51^{\mathrm{a}}(.05)$ \\
\hline Social Closeness & $.40^{\mathrm{a}}(.08)$ & $.19(.22)$ & $.19^{\mathrm{a}}(.09)$ & $.41^{\mathrm{a}}(.05)$ \\
\hline Stress Reaction & $.53^{\mathrm{a}}(.04)$ & $.49(.17)$ & $.00^{\mathrm{b}}$ & $.47^{\mathrm{a}}(.04)$ \\
\hline Alienation & $.45^{\mathrm{a}}(.13)$ & $.50^{\mathrm{b}}$ & $.11(.12)$ & $.44^{\mathrm{a}}(.04)$ \\
\hline Aggression & $.44^{\mathrm{a}}(.05)$ & $.27(.19)$ & $.00^{\mathrm{b}}$ & $.56^{\mathrm{a}}(.05)$ \\
\hline Control & $.44^{\mathrm{a}}(.05)$ & $.00^{\mathrm{a}, \mathrm{b}}$ & $.00^{\mathrm{b}}$ & $.56^{\mathrm{a}}(.05)$ \\
\hline Harm Avoidance & $.55^{\mathrm{a}}(.04)$ & $.31 \quad(.15)$ & $.00^{\mathrm{b}}$ & $.45^{\mathrm{a}}(.04)$ \\
\hline Traditionalism & $.45^{\mathrm{a}}(.10)$ & $.50^{\mathrm{b}}$ & $.12(.10)$ & $.43^{\mathrm{a}}(.04)$ \\
\hline Absorption & $.50^{\mathrm{a}}(.10)$ & $.50^{\mathrm{b}}$ & $.03(.10)$ & $.47^{\mathrm{a}}(.04)$ \\
\hline Positive Emotionality & $.40^{\mathrm{a}}(.08)$ & $.00^{\mathrm{a}, \mathrm{b}}$ & $.22^{a}(.07)$ & $.38^{\mathrm{a}}(.04)$ \\
\hline Negative Emotionality & $.55^{\mathrm{a}}(.11)$ & $.50^{\mathrm{b}}$ & $.02(.11)$ & $.43^{\mathrm{a}}(.04)$ \\
\hline Constraint & $.58^{\mathrm{a}}(.04)$ & $.40 \quad(.14)$ & $.00^{\mathrm{b}}$ & $.43^{a}(.04)$ \\
\hline
\end{tabular}

Note. Standard errors are in parentheses.

a Significantly different from null value at $p<.05$. ${ }^{\mathrm{b}}$ Boundary solution; therefore, no standard error computed. 
With respect to its environmental origins, Positive Emotionality contrasts with the other two higher order MPQ dimensions, Negative Emotionality and Constraint, which show no shared family environmentality. Of these three, Positive Emotionality (extraversion) is most clearly an affective-interactive dimension. High Positive Emotionality is characterized by active engagement with one's environment, whereas low Positive Emotionality is characterized by weak engagement or disengagement. Because of its inherently interactive-communicative character, it seems plausible that a person's Positive Emotionality trait level is particularly responsive to and reflective of the surrounding social climate, including the prevailing and more or less engaging climate of the rearing environment.

Of the primary scales, only Social Closeness exhibited a significant shared family-environmental component. Although Social Closeness is a secondary marker of Positive Emotionality, it is the main marker of one of the major MPQ dimensions that emerge when four, rather than three, second-order factors are extracted. In the four-factor solution, Positive Emotionality essentially is split into Agentic Positive Emotionality and Communal Positive Emotionality, with Achievement being the salient marker of the former and Social Closeness of the latter. It is interesting to contrast Social Closeness with Social Potency, which is more "agentic" than Social Closeness and does not have a significant shared family-environment component.

Social Closeness and Social Potency represent the basic dimensions (sometimes called affiliation and control, respectively) in interpersonal theory (Kiesler, 1983; Wiggins, 1982). As explained by Kiesler, behavior variations along these two continua differ with respect to the complementary responses that each invites and by which they are sustained. High and low affiliativeness are complemented by similar behaviors (affiliativeness by affiliativeness, nonaffiliativeness by nonaffiliativeness). High and low control, on the other hand, are complemented by their opposites (dominance "pulling" submissiveness and vice versa). Given these dynamics, we would expect that family environments tend to provide more uniform familyinteraction norms with respect to affiliativeness than to control. Thus, the communal facet of Positive Emotionality may be particularly responsible for its shared family environmentality.

Our findings suggest more saliently, nonetheless, that the common environment generally plays a very modest role in the determination of many personality traits. This conclusion is now supported by studies using samples of four different types: twins reared together, twins reared apart, adoptive parents and their offspring, and adoptive siblings. It runs counter, however, to the belief, influential among psychologists, that personality similarity is profoundly enhanced by a shared family environment. Mischel (1981) has confronted this issue directly:

Genes and glands are obyiously important, but social learning also has a dramatic role. Imagine the enormous differences that would be found in the personalities of twins with identical genetic endowments if they were raised apart in two different families. . . . Through social learning vast differences develop among people in their reactions to most stimuli they face in daily life. (p. 311 )

Although some psychologists (e.g., Feshbach \& Weiner, 1986; Liebert \& Spiegler, 1987; Singer, 1984) have been impressed by the genetic implications of personality similarities in twins reared together, others attribute much of this resemblance to reciprocal influences, to more similar treatment, and to greater expectations of behavioral similarity accorded by their families to monozygotic twins who look so much alike.

The remarkably similar overall magnitude of the MZA and MZT intraclass correlations deserves special mention in this connection. Slight family-environment effects do indeed entail highly similar MZA and MZT correlations. Although surprising, these results are entirely consistent with reported data on ordinary twins and data from adoption studies.

In our own case, it was unexpected that the Traditionalism scale (measuring endorsement of traditional moral and family values) did not show a systematic familial environmental effect. To find such an effect may, however, require a different model. It is possible, for example, that for some traits, including Traditionalism, the co-twin is a particularly important similarity-inducing component of the common family environment of twins reared together and that this assimilative co-twin influence is potentiated only to the extent that genetically determined, within-pair differences exist to begin with, as among $\mathrm{DZ}$ twins but not $\mathrm{MZ}$ twins. In that case, one would expect the increase in within-pair similarity of DZTs, relative to DZAs, to be larger than that of MZTs relative to MZAs (as the Traditionalism data may suggest). Although only conjectures at this point, these ideas at least illustrate the need for exploring a wider range of gene-environment models (and for going beyond a study of assortative mating that would also be indicated in a full-fledged analysis of Traditionalism).

In the area of personality development, studies that limit examination to variables such as social class, child-rearing patterns, and other common-environment characteristics of intact biological families cannot be decisive because they confound genetic and environmental factors. In light of studies that have provided pertinent data, it is evident that new designs and theoretical approaches to personality development are needed (Plomin \& Daniels, 1987; Rowe \& Plomin, 1981; Scarr \& McCartney, 1983). Particularly helpful would be research on individual rearing environments that would identify psychologically meaningful components of the unshared environment and separate these from measurement error and other trait-irrelevant variance. On the other hand, only so much meaningful information can be recovered from this source of variation. As indicated earlier, our guess is that 15 to $30 \%$ of the observed variance is nontrait variance, all of it concentrated in the unshared environment component. From the last column of Table 5 we can see that unshared environmentality estimates vary around $45 \%$. A ceiling of $45 \%$ does not exceed the conjectured 15 to $30 \%$ noise baseline by a large margin. A realistic pursuit of meaningful unshared variance components cannot overlook these limits, which may be more restrictive in some areas than in others.

Our results also bear on the question of differential heritability. We find indications of differences in heritability among the various relatively independent traits measured by the MPQ. We are not arguing, then, that given sufficient power no substantial differences in heritability can be found between some personality traits. On the other hand, our data indicate (consistent with other studies) that several diverse personality variables have comparable heritabilities. The same point is illustrated in a 
study by Rushton, Fulker, Neale, Nias, and Eysenck (1986), who found that measures of altruism and aggression (traits expected a priori to be heavily influenced by socialization processes) both had heritabilities of about .50 and no common family-environment influence.

It should be kept in mind that heritability estimates can vary depending on the genetic model that is being fit to the data. Clarification of the differential-heritability issue will, therefore, partly depend on better understanding of the genetic architecture underlying different personality traits. This leads us to our final major point.

Although most previous analyses of personality data have led to the acceptance of a simple additive genetic model, this view has recently been challenged (Carey \& Rice, 1983; Lykken, 1982; Lykken \& Bouchard, 1983/84; Lykken et al., 1982). Carey and Rice (1983) concluded that the "genetic and environmental architecture of personality may be complex and traitspecific" (p. 54). The Carey and Rice analysis was carried out on three MPQ scales, Social Potency, Social Closeness, and Control (previously named impulsivity and scored in the reverse direction). Our own results also suggest that the simple additive model has to be rejected in some cases. Only the complete four-parameter model accommodated all of the data, and it indicated nonadditivity for three scales: Social Potency, Control, and Positive Emotionality. The nonadditivity patterns encountered in these cases are consistent with an epistatic interpretation and in this sense support the concept of emergenesis discussed in the introduction.

In this study, purely additive genetic models were nevertheless found to fit the data well in many cases. Larger sample sizes, particularly more DZAs, and additional family groups (including offspring of twins) would better enable us to determine the comparative adequacy of additive, nonadditive, and combined additive-nonadditive genetic models; to isolate dominant and epistatic components of the nonadditive genetic variance; and to examine further the effect of systematic environmental influences on $\mathrm{MZ}$ and $\mathrm{DZ}$ twin similarity through environmental assessments. We hope to expand our data base in these directions.

\section{References}

Ahern, F. M., Johnson, R. C., Wilson, J. R., McClearn, G. E., \& Vandenberg, S. G. (1982). Family resemblances in personality. Behavior Genetics, 12, 261-280.

Bentler, P. M., \& Bonett, D. G. (1980). Significance tests and goodness of fit in the analysis of covariance structure. Psychological Bulletin, $88,588-606$.

Block, J. (1964). The challenge of response sets. New York: AppletonCentury-Crofts.

Bouchard, T. J., Jr. (1984). Twins reared apart and together: What they tell us about human diversity. In S. Fox (Ed.), The chemical and biological bases of individuality (pp. 147-184). New York: Plenum Press.

Carey, G., Goldsmith, H. H., Tellegen, A., \& Gottesman, I. I. (1978). Genetics and personality inventories: The limits of replication with twin data. Behavior Genetics, 8, 299-313.

Carey, G., \& Rice, J. (1983). Genetics and personality temperament: Simplicity or complexity? Behavior Genetics, 13, 43-63.

Conley, J. J. (1984). The hierarchy of consistency: A review and model of longitudinal findings on adult individual differences in intelligence, personality and self-opinion. Personality and Individual Differences, 5, 11-25.

Costa, P. T., \& McCrea, R. R. (1980). Influence of extraversion and neuroticism on subjective well-being: Happy and unhappy people. Journal of Personality and Social Psychology, 38, 668-678.

Cudeck, R., \& Browne, M. W. (1983). Cross-validation of covariance structures. Multivariate Behavioral Research, 18, 147-167.

Depue, R. A., Krauss, S., \& Spoont, M. R. (1987). A two-dimensional threshold model of seasonal bipolar affective disorder. In D. Magnusson \& A. Ohrman (Eds.), Psychopathology: An interactional perspective (pp. 95-123). New York: Academic Press.

Eaves, L. J. (1978). Twins as a basis for the causal analysis of human personality. In W. E. Nance, G. Allen, \& P. Parisi (Eds.), Twin research: Psychology and methodology (pp. 151-174). New York: Alan R. Liss.

Eaves, L. J. (1982). The utility of twins. In V. E. Anderson, W. A. Hauser, J. K. Penry, \& C. F. Sing (Eds.), Genetic basis of the epilepsies (pp. 249-276). New York: Raven Press.

Eaves, L. J., Last, K. A., Young, P. A., \& Martin, N. G. (1978). Model fitting approaches to the analysis of human behavior. Heredity, 41, 249-320.

Eaves, L. J., \& Young, P. A. (1981). How stable are personality traits? In L. Gedda, P. Parisi, \& W. E. Nance (Eds.), Twin research 3: Part B. Intelligence, personality and development (pp. 87-97). New York: Alan R. Liss.

Eysenck, H. J., \& Eysenck, S. B. G. (1975). Manual of the Eysenck Personality Questionnaire. San Diego, CA: Educational and Industrial Testing Service.

Falconer, D. S. (1960). Introduction to quantitative genetics. New York: Ronald Press.

Feshbach, S., \& Weiner, B. (1986). Personality (2nd ed.). Lexington, MA: Heath.

Goldberg, L. R. (1981). Language and individual differences: The search for universals in personality lexicons. In C. Wheeler (Ed.), Review of personality and social psychology (Vol. 2, pp. 141-165). Beverly Hills, CA: Sage.

Goldsmith, H. H. (1983). Genetic influences on personality from infancy to adulthood. Child Development, 54, 331-335.

Gray, J. A. (1973). Causal theories of personality and how to test them. In J. R. Royce (Ed.), Multivariate analysis and psychological theory (pp. 409-463). New York: Academic Press.

Gray, J. A. (1981). A critique of Eysenck's theory of personality. In H. J. Eysenck (Ed.), A model for personality (pp. 233-252). Berlin: Springer-Verlag.

Heath, A. C., Martin, N. G., \& Eaves, L. J. (1984). Sense and nonsense in genetic epidemiology: A critique of the statistical model of Williams and Iyer. Acta Geneticae Medicae et Gemellologiae, 33, 557563.

Hewitt, J. K. (1984). Normal components of personality variation. Journal of Personality and Social Psychology, 47, 671-675.

Jinks, J. L., \& Fulker, D. W. (1970). A comparison of the biometrical genetical, MAVA, and classical approaches to the analysis of human behavior. Psychological Bulletin, 73, 311-349.

Kiesler, D. J. (1983). The 1982 interpersonal circle: A taxonomy for complementarity in human transactions. Psychological Review; 90, $185-214$

Liebert, R. M., \& Spiegler, M. D. (1987). Personality: Strategies and issues (5th ed.). Homewood, IL: Dorsey Press.

Loehlin, J. C. (1982). Are personality traits differentially heritable? Behavior Genetics, 12, 417-428.

Loehlin, J. C., Horn, J. M., \& Willerman, L. (1981). Personality resemblance in adoptive families. Behavior Genetics, 11, 309-330.

Loehlin, J. C., \& Nichols, R. C. (1976). Heredity, environment and per- 
sonality: A study of 850 sets of twins. Austin: University of Texas Press.

Lykken, D. T. (1968). Statistical significance in psychological research. Psychological Bulletin, 70, 151-159.

Lykken, D. T. (1978). The diagnosis of zygosity in twins. Behavior Genetics, 8, 437-473.

Lykken, D. T. (1982). Research with twins: The concept of emergenesis. Psychophysiology, 19, 361-373.

Lykken, D. T., \& Bouchard, T. J., Jr. (1983/84). Genetische Aspekte menschlicher Individualität [Genetic aspects of human individuality]. In H. V. Ditfurth (Ed.), Mannheimer Forum 1983/84 (pp. 79 117). Hamburg: Hoffman and Campe Verlag.

Lykken, D. T., Tellegen, A., \& Iacono, W. G. (1982). EEG spectra in twins: Evidence for a neglected mechanism of genetic determination. Physiological Psychology, 10, 60-65.

Martin, N. G., Eaves, L. J., Kearsey, M. J., \& Davies, P. (1978). The power of the classical twin study. Heredity, 40,87-116.

McGue, M., \& Bouchard, T. J. (1984). Adjustment of twin data for the effects of age and sex. Behavior Genetics, 14, 325-343.

Meehl, P. E. (1978). Theoretical risks and tabular risks: Sir Karl, Sir Ronald, and the slow progress of soft psychology. Journal of Consulting and Clinical Psychology, 46, 806-834.

Megargee, E. I. (1972). The California Psychological Inventory handbook. San Francisco: Jossey-Bass.

Mischel, W. (1981). Introduction to personality (3rd ed.). New York: Holt, Rinehart \& Winston.

Nance, W. E., \& Corey, L. A. (1976). Genetic models for the analysis of data from the families of identical twins. Genetics, 83, 811-826.

Nichols, R. C. (1978). Twin studies of ability, personality, and interests. Homo, 29, 158-173.

Plomin, R., \& Daniels, D. (1987). Why are children in the same family so different from one another? Behavioral and Brain Sciences, 10, 116.

Price, R. A., Vandenberg, S. G., Iyer, H., \& Williams, J. S. (1982). Components of variation in normal personality. Journal of Personality and Social Psychology, 43, 328-340.

Rose, R. J., Boughman, J. A., Corey, L. A., Nance, W. E., Christian, J. C., \& Kang, K. W. (1980). Data from kinships of monozygotic twins indicate maternal effects on verbal intelligence. Nature, 283 , 375-377.

Rowe, D. C., \& Plomin, R. (1981). The importance of nonshared (E1) environmental influences in behavioral development. Developmental Psychology, 17, 517-531.
Rushton, J. P., Fulker, D. W., Neale, M. C., Nias, D. K. B., \& Eysenck, H. J. (1986). Altruism and aggression: To what extent are individual differences inherited? Journal of Personality and Social Psychology, 50, 1192-1198.

Scarr, S., \& McCartney, K. (1983). How people make their own environments: A theory of genotype-environment effects. Child Development, 54, 424-435.

Scarr, S., Weber, P. L., Weinberg, R. A., \& Wittig, M. A. (1981a). Personality resemblance among adolescents and their parents in biologically related and adoptive families. Journal of Personality and Social PSychology, 40, 885-898.

Scarr, S., Weber, P. L., Weinberg, R. A., \& Wittig, M. A. (1981b). Personality resemblance among adolescents and their parents in biologically related and adoptive families. In L. Gedda, P. Parisi, \& W. E. Nance (Eds.), Twin Research 3: Part B. Intelligence, personality and development (pp. 99-120). New York: Alan R. Liss.

Singer, J. L. (1984). The human personality. New York: Harcourt Brace Jovanovich.

Tellegen, A. (1982). Brief manual for the Differential Personality Questionnaire. Unpublished manuscript, University of Minnesota, Minneapolis.

Tellegen, A. (1985). Structure of mood and personality and their relevance to assessing anxiety, with an emphasis on self-report. In A. H. Tuma \& J. D. Maser (Eds.), Anxiety and the anxiety disorders (pp. 681-706). Hillsdale, NJ: Erlbaum.

Warr, P., Barter, J., \& Brownbridge, G. (1983). On the independence of positive and negative affect. Journal of Personality and Social Psychology, 44, 644-651.

Watson, D., \& Clark, L. A. (1984). Negative Affectivity: The disposition to experience aversive emotional states. Psychological Bulletin, 96, $465-490$.

Watson, D., \& Tellegen, A. (1985). Toward a consensual structure of mood. Psychological Bulletin, 98, 219-235.

Wiggins, J. S. (1982). Circumplex models of interpersonal behavior in clinical psychology. In P. C. Kendall \& J. N. Butcher (Eds.), Handbook of research methods in clinical psychology (pp. 183-221). New York: Wiley.

Zonderman, A. B. (1982). Differential heritability and consistency: A reanalysis of the NMSQT CPI data. Behavior Genetics, 12, 193-208.

Received March 21, 1986

Revision received August 31, 1987 Accepted October 30, 1987 